\title{
Antibiotic yields anxiolytic
}

Benzodiazepines such as diazepam are commonly prescribed to control anxiety, and act by enhancing the action of the neurotransmitter $\operatorname{GABA}(\gamma$-aminobutyric acid) at the brain GABA receptor. But drugs of this class have sedative side effects, spurred a search for alternatives by Kelvin Gee and colleagues. In a Nature Medicine advanced online publication, the team describe a first-in-class anxiolytic that is free of sedative side effects.

The search strategy devised by Gee et al. was based on the hypothesis that mitigation of side effects might be achieved by targeting non-benzodiazepine-binding sites of $\mathrm{GABA}_{\mathrm{A}}$ receptors. Compounds related to the fluoroquinolone antibiotic norfloxacin were chosen as screening candidates for two reasons: first, a small proportion of patients taking this antibiotic experience anxiety as a side effect; second, norfloxacin is known to antagonize $\mathrm{GABA}_{\mathrm{A}}$ receptors at an undefined site. So, chemical modification of norfloxacin could generate compounds with the opposite, GABA-enhancing anxiolytic effect.

In a standard assay for GABA modulation, several norfloxacinrelated chemotypes inhibited the binding of the convulsant TBPS to $\mathrm{GABA}_{\mathrm{A}}$ receptors. Analysis of the most active product, dubbed compound 4, showed that this compound does not act directly on the $\mathrm{GABA}_{\mathrm{A}}$ receptor-binding sites for TBPS, norfloxacin, benzodiazepines or GABA. an undesirable feature that has

To confirm the GABA-modulatory action of compound 4, electrophysiological studies were conducted on HEK293 cells expressing different human $\mathrm{GABA}_{\mathrm{A}}$ receptor subtypes. Compound 4 enhanced GABAmediated currents in a dosedependent manner, but only in those cells that expressed the $\alpha_{2}$ subunit of the receptor. Failure of the benzodiazepine binding-site antagonist flumazenil to block this potentiation confirmed that compound 4 binds to a non-benzodiazepine site. So structural manipulation of norfloxacin did produce a compound that binds to an alternative $\mathrm{GABA}_{\mathrm{A}}$ receptor site, but did this modification result in anxiolytic rather than anxiety-inducing effects?

In two rodent models of anxiety, treatment with compound 4 relieved anxiety-related behaviour. Notably, the magnitude of this effect was comparable to that afforded by diazepam. But the real breakthrough came from assessments of motor performance using the rotarod test — diazepam caused motor impairment whereas compound 4 did not, even at the maximal soluble dose. Compound 4 might therefore be at the forefront of a new approach to the design of robust anxiolytics with improved side-effect profiles.

\section{(0) References and links} ORIGINAL RESEARCH PAPER Johnstone, T. B. C. et al. Modifying quinolone antibiotics yields new anxiolytics. Nature Med. 30 November 2003 (doi: $10.1038 / \mathrm{nm} 967$ )

FURTHER READING Christopoulos, A. Allosteric binding sites on cell-surface receptors: novel targets for drug discovery. Nature Rev. Drug Discov. 1, 198-210 (2002)

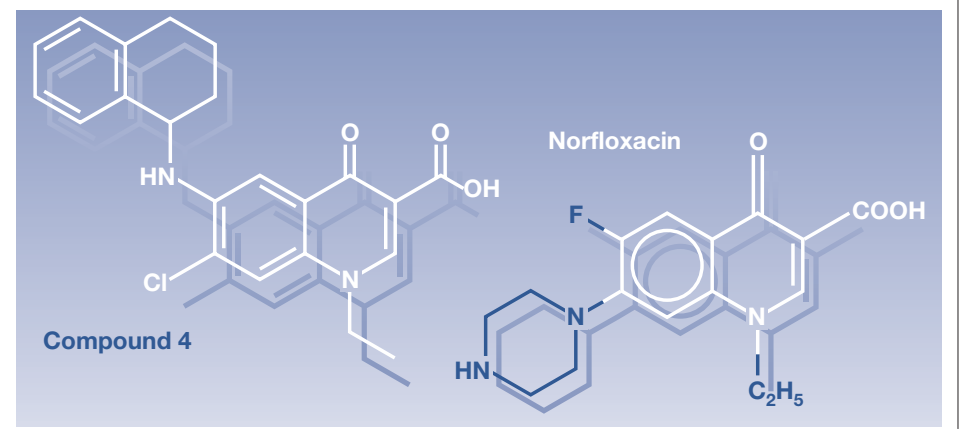

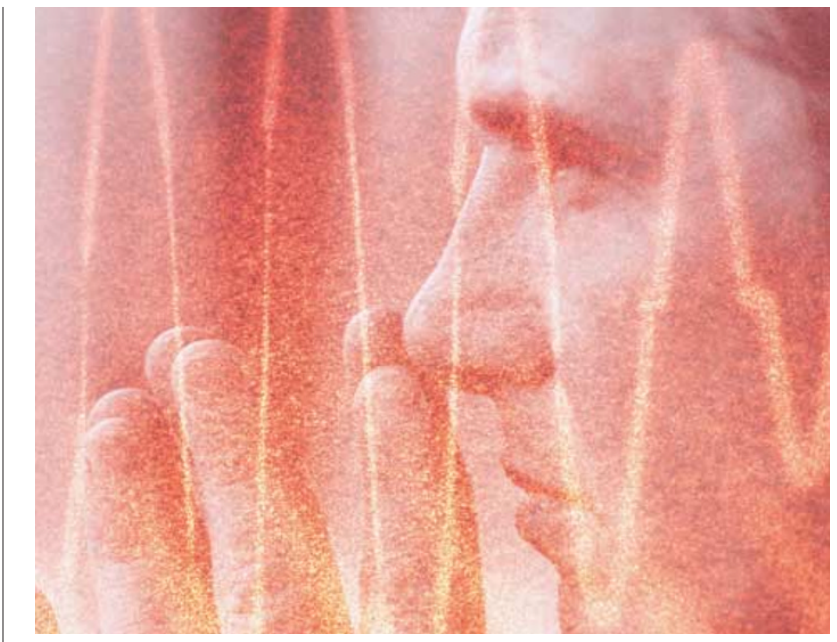

MEMORY

\section{Oscillations predict recall}

If a magician gave you a list of words to memorize, and was then able to predict precisely which words you would be able to recall, you would no doubt be impressed. Reporting in the Journal of Neuroscience, Sederberg and colleagues show that this feat can be achieved without resorting to magic or 'mind-control' tricks. Using intracranial recordings from the cortex, they identified specific patterns of rhythmic neuronal activity that correlated with successful memory formation.

Sederberg $e$ al. used a group of 10 patients, aged from 8-17, each of whom had up to 128 electrodes implanted into their brains to monitor epilepsy. The patients were asked to memorize a list of 20 common nouns while the authors recorded their cortical and subcortical brain activity. The patients were then asked to recall as many words as possible, after being distracted briefly with an arithmetical task to reduce bias towards the most recently presented words.

The authors observed increases in both low-frequency theta oscillations $(4-8 \mathrm{~Hz})$ and high-frequency gamma oscillations $(28-64 \mathrm{~Hz})$ during the presentation of words that were subsequently recalled successfully. The theta oscillations were detected largely in the right temporal and frontal cortex, whereas the gamma oscillations were more widespread.

What is the importance of gamma and theta power for memory formation? Both types of activity have been implicated in processes that are crucial to memory encoding - gamma oscillations in attention, and theta oscillations in long-term potentiation. Approaches such as that of Sederberg et al. should help us to understand how different cortical regions are recruited to these processes as new memories are laid down, and to clarify the precise role of this rhythmic activity in memory formation.

\section{(D) References and links}

Heather Wood

ORIGINAL RESEARCH PAPER Sederberg, P. B. et al. Theta and gamma oscillations

ORIGINAL RESEARCH PAPER Sederberg, P. B. et al. Theta and gamma oscillation
during encoding predict subsequent recall. J. Neurosci. 23, 10809-10814 (2003) FURTHER READING Paller, K. A. \& Wagner, A. D. Observing the transformation of experience into memory. Trends Cogn. Sci. 6, 93-102 (2002) WEB SITE

Encyclopedia of Life Sciences: http://www.els.net/ Learning and memory 